\title{
Generalized Stochastic Petri-Net Algorithm with Fuzzy Parameters to Evaluate Infrastructure Asset Management Policy
}

DOI:

10.1109/FUZZ48607.2020.9177562

\section{Document Version}

Accepted author manuscript

Link to publication record in Manchester Research Explorer

Citation for published version (APA):

Sachan, S., \& Donchak, N. (2020). Generalized Stochastic Petri-Net Algorithm with Fuzzy Parameters to Evaluate Infrastructure Asset Management Policy. In IEEE Xplore https://doi.org/10.1109/FUZZ48607.2020.9177562

\section{Published in:}

IEEE Xplore

\section{Citing this paper}

Please note that where the full-text provided on Manchester Research Explorer is the Author Accepted Manuscript or Proof version this may differ from the final Published version. If citing, it is advised that you check and use the publisher's definitive version.

\section{General rights}

Copyright and moral rights for the publications made accessible in the Research Explorer are retained by the authors and/or other copyright owners and it is a condition of accessing publications that users recognise and abide by the legal requirements associated with these rights.

\section{Takedown policy}

If you believe that this document breaches copyright please refer to the University of Manchester's Takedown Procedures [http://man.ac.uk/04Y6Bo] or contact uml.scholarlycommunications@manchester.ac.uk providing relevant details, so we can investigate your claim.

\section{OPEN ACCESS}




\section{Generalized Stochastic Petri-Net Algorithm with Fuzzy Parameters to Evaluate Infrastructure Asset Management Policy}

\author{
Swati Sachan \\ Decision and Congnative Research Centre \\ Alliance Manchester Business School \\ The University of Manchester \\ Manchester, United Kingdom \\ swati.sachan@manchester.ac.uk
}

\author{
Nishant Donchak \\ LNG Quest Limited \\ London, United Kigndom, SW1P 2QB \\ nishant.donchak@lngquest.co.uk
}

\begin{abstract}
Infrastructure asset owners develop strategies to maximize asset availability and minimize economic losses due to the failure of critical assets. Infrastructure asset management policy involves the strategic development of inspection, repair and renewal plans. The policy evaluation support decisionmakers in assessing its impact on the reliability of the assets. This paper attempts to show the procedure to evaluate these policies through Generalized Stochastic Petri-Net with fuzzy parameters. The stochasticity allows representation of randomness in a system and fuzziness support incorporation of uncertain information from experts. It can be used periodically to estimate the type and number of actions required to maintain assets in good operating condition over the planning horizon. The methodology is demonstrated on the evaluation of maintenance policy of supplementary drive and slide chair in railway switches $\&$ crossing.
\end{abstract}

Keywords— policy, petri-net, stochastic, fuzzy, asset, railway

\section{INTRODUCTION}

Asset holder implements various maintenance policy to ensure reliability and availability of critical infrastructure to provide continuous facilities and services to a country or a city. The critical infrastructures are large scale spatially distributed systems and networks such as transportation (road and rail), water supply, electricity supply, and information and communication systems. Failures in these infrastructures cause huge economic losses and disruption in the effective and efficient functioning of society. Failures occur in weak assets due to insufficient inspection and maintenance practices performed under ineffective asset management policy. Infrastructure asset management policy involves the strategic development of inspection, repair and renewal plan for assets. The policy developed by asset holders may shortfall the expectations if it is not evaluated and assess regularly.

Stochastic petri nets (SPN) is a powerful method which combines the intuitive graphical and mathematical representation of random, concurrent and synchronised processes in systems [1][2]. Petri-net is used as a modelling tool to overcome the limitation of the Markov process. The memoryless property of Markov approach restricts the ability of the model to consider the maintenance history, as the future states in Markov model depend only on the current state and not on the history of arrival at the current state. Petri-net has been widely used in modelling business processes $[3][4][5][6][7]$ and engineering processes specifically in manufacturing and control engineering [8][9][10][11][12]. In past few years, its application in asset management has received a great deal of attention to model degradation process and maintenance $\&$ renewal process of assets in wind turbine [13][14], railway [15][16][17][18] and bridges [19][20]. The main characteristic of SPN is its ability to support structural organization and visualization of knowledge or information related to asset degradation and its maintenance policy in different situations. Development of petri-net for asset management problems is complex as it requires gathering information related to different degradation levels of an asset and maintenance policy by an asset holder at different degradation level. The crucial steps required to evaluate maintenance policy at different degradation level in a planning horizon is similar for all assets. The parameters in SPN are obtained from experts or it could be the outcome of the statistical models. The acquisition of an accurate value of parameters and its justification is the most difficult part of designing a generalized stochastic petri-net. The SPN can handle randomness due to stochastic nature however, it cannot handle uncertainty in the value of the parameters. This paper attempts to show procedure through an algorithm which would lead to a computer program and to help researchers and practitioners in applying generalized stochastic petri-net with fuzzy parameters to solve asset management problems with a better understanding of its requirements and capabilities. The fuzzy parameters enable the inclusion of uncertain and precise information.

The rest of paper is organized as follows. Section II describes the generalized stochastic petri net (GSPN) and types of transitions. Section III, show the data structure and algorithm for evaluation of asset management policy by GSPN. Section IV presents the case study on components of railway switches \& crossing. The paper is concluded in section V.

\section{Generlized Stochastic Petri Net With FuZZY PARAMETERS}

\section{A. Generlized Stochastic Petri Net}

A petri-net is a bipartite graph used to model the concurrency and synchronization in a system. It is composed of four main elements places, transitions, arcs and tokens. A circle, bar or rectangular box, arrows and dot symbols are used to represent a place, a transition, pre-condition and postcondition of transition, and a token in a place, respectively. The tokens circulate in the petri-net between places. The position of token displays the current state of the system. In a 
petri-net, tokens move between places according to the firing rules for transitions. A transition is activated to fire when each place connects to the input arc has at least one or more tokens. The firing of a transition removes tokens from input places and deposit a token in output place. The number of tokens required in input places depends on the activation rule of a transition, sometimes a place requires two or more tokens. The Generalized Stochastic Petri Nets (GSPN) is an extension of Stochastic Petri Net. The GSPN is adequate for the representation of discrete event dynamic system since it can capture the dynamic behaviour of the system and support the automatic construction of stochastic process. It has two types of the transition, timed transitions and immediate transition and the subsequent marking obtained by firing these transitions is called tangible and vanishing marking, respectively. The marking process of a GSPN is a generalized semi-Markov process (GSMP) which is similar to discrete event simulation. Therefore, the descriptive power of a GSPN model is the same as that of discrete event simulation.

\section{B. Types of transition}

A transition represents a change in the state of the system. The firing of transitions indicates the occurrence of an event. There are different types of transitions in a GSPN to effectively capture the dynamic behaviour of an asset.

- Stochastic and deterministic timed transition, $\mathrm{T}_{1} \subseteq \mathrm{T}$ : Timed transitions are fired after a delay time. The delay is obtained from the probability density function (PDF). The stochastic time for transition is obtained from PDF such as Weibull and Normal distribution. Fig. 1 shows the stochastic and deterministic transitions. The deterministic transition time is fixed. It is obtained from a uniform distribution. Each component of an asset has different stages of degradation. The type of maintenance action depends on the degradation state. The parameters for delaytime distributions are obtained from experts, maintenance guidelines, statistical and physics-based models. The acquisition of a precise value of a parameter for transition for different types of events is very challenging. Therefore, instead of assuming an idle crisp parameter it would be convenient to use fuzzy parameters. A fuzzy set $\tilde{A}$ on membership function $\mu_{\tilde{a}}$ for universal the value of $x \in \mathrm{X}$ can be written as:

$$
\tilde{A}=\left\{\left(x, \mu_{\tilde{a}}\right) \mid x \in \mathrm{X}\right\}
$$

$\mu_{\tilde{a}}$ is a membership function. It maps $X$ to a membership space $[0,1]$. A fuzzy set $\tilde{A}$ get support from a crisp subset of X. The $\alpha$-cut of a fuzzy set for a level $\alpha \in[0,1]$ is a crisp subset of $\mathrm{X}$ having membership greater than equal to $\alpha$ can be written as:

$$
\tilde{A}_{\alpha}=\left\{\left(x, \mu_{\tilde{a}} \geq \alpha\right) \mid x \in \mathrm{X}, \alpha \in[0,1]\right\}
$$

There are different types of fuzzy numbers such as triangular, trapezoidal and Gaussian. A fuzzy number can be used to represent uncertain parameters in GSPN by randomizing value of $\alpha$. Then, generating $\alpha$-cut of a fuzzy set containing a crisp subset of $X$ having membership function greater than $\alpha, \mu_{\tilde{a}} \geq \alpha$. The $\alpha$ cut of a fuzzy set is defuzzified to obtain crisp real number corresponding to a particular type of fuzzy number. The crispness of $\alpha$-cut fuzzy set increases with the $\alpha$ level. For example, suppose delay time of transition from state $s_{1}$ to $s_{2}$ is given by Weibull distribution $f(t \mid \beta, \eta)$, here $\beta$ and $\eta$ are shape and scale parameter. In asset management, $\eta$ is usually the lifetime of the asset or time to reach a certain degradation level. Let unit of $\eta$ is the number of days. The value of $\eta$ is uncertain and it is described by a triangular fuzzy number $\mu_{\tilde{a}}=(l, m, u)=$ $(3000,3650,4500)$, shown in Fig. 2. Here, $l, m, u$ is lower, middle and upper value, respectively. The crisp real number is found by defuzzification of crisp subset of $\eta$ in an $\alpha$-cut of fuzzy set. The $\alpha$-cut fuzzy set can defuzzified by methods such as the mean value of statistical Beta distribution [21] and centroid defuzzification [22]. At $\alpha=0$, fuzzy number $\eta=$ $[l, u]$ and $\alpha=1$, a fuzzy number for $\eta=m$.

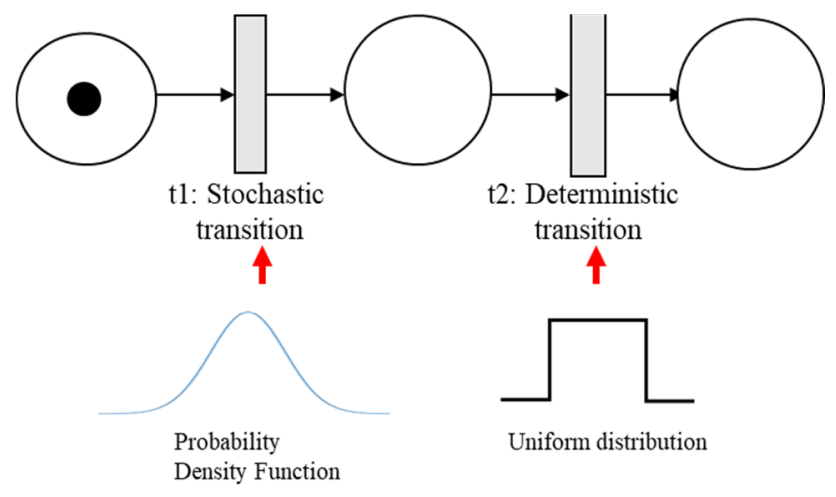

Fig. 1. Stochastic and deterministic transition

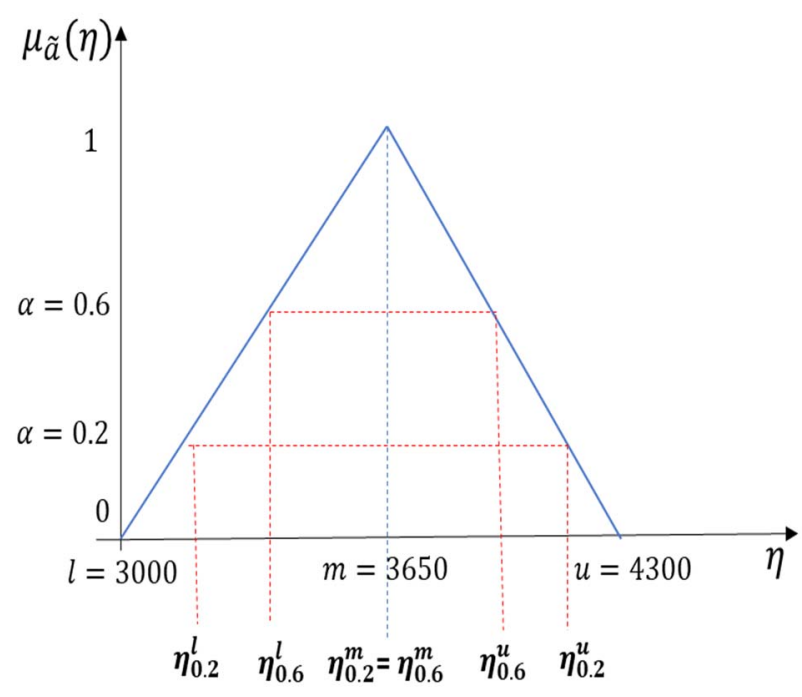

Fig. 2. Fuzzy parameter

- Immediate transition, $\mathrm{T}_{2} \subset \mathrm{T}:$ The firing time of immediate transition is set to zero.

$$
\mathrm{T}_{1} \cap \mathrm{T}_{2}=\varnothing \text { and } \mathrm{T}=\mathrm{T}_{1} \cup \mathrm{T}_{2}
$$

- Reset transition: It is an immediate transition where tokens from all the places are removed and are deposited back to the places which represent good as new state and its corresponding maintenance state. This type of transition is used when an asset is renewed. 
A petri-net has conflicting structure when an input has two or more output transitions as shown in Fig. 3, the transition $T$ and $T^{\prime}$ are in conflict. Both transitions are enabled due to token in a place $P^{\prime}$, however only one can fire at a time. The firing of one transition leads to the disability of other transitions. Such type of a petri-net structure requires a conflict resolution mechanism. The conflict is resolved in a non-deterministic way by assigning an appropriate probability and weight to the conflicting timed and immediate transition, respectively. If $T$ and $T^{\prime}$ are timed transitions then, they will fire after delay time $t$ and $t^{\prime}$ with probability $\frac{\lambda}{\lambda+\lambda^{\prime}}$ and $\frac{\lambda^{\prime}}{\lambda+\lambda^{\prime}}$ , respectively. If $T$ and $T^{\prime}$ are immediate transitions, then their firing rate depends on the weight of transition $\frac{w}{w+w^{\prime}}$ and $\frac{w^{\prime}}{w+w^{\prime}}$, respectively. A transition fires only when it is enabled, and its associated condition of enabling the transition is true.

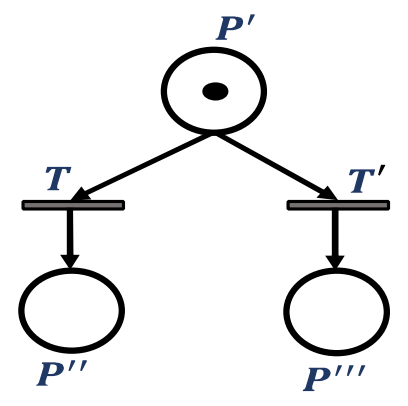

Fig. 3. Conflict resolution

\section{Definition of GSPN}

A Generalized Stochastic Petri Net is eight-tuple, GSPN $=\left(P, T, T_{1}, T_{2}, W, I^{-}, I^{+}, M_{0}\right)$ where:

1) $P=\left\{p_{1}, \ldots, p_{n}\right\}$ is a finite and non-empty set of places

2) $T=\left\{t_{1}, \ldots, t_{m}\right\}$ is a finite and non-empty set of transitions

3) $P \cap T=\varnothing$

4) $T_{1} \subseteq T$ is a set of timed transition

5) $T_{2} \subset T$ is a set of immediate transition, where $T_{1} \cap$ $T_{2}=\varnothing$ and $T=T_{1} \cup T_{2}$

6) $W=\left\{w_{1}, \ldots, w_{|T|}\right\}$ is an array in which the entry $w_{y} \in R^{+}$is a delay in transition $t_{y} \in T_{1}$ and immediate firing of transition $t_{y} \in T_{2}$. The delay in transition specifies the time that a transition needs to be enabled before it fires. The delay time is defined by a probability distribution function (PDF) that describes the possibly random delay time. The firing time of immediate transition is set to zero. An immediate transition is given priority by allocating higher weight to the transition compared to other.

7) $I^{-}$and $I^{+}$are backward and forward incident function defined on $P \times T$, respectively. The backward $I^{-}(p, t)$, and forward $I^{+}(p, t)$ incident function depicts the number of tokens removed and added in pre-place and post-place when a transition is fired

8) The marking $M$ of the Petri net associates a (nonnegative integer) number of tokens to each place $M: P \rightarrow N$. The marking can be viewed as an array of natural numbers $M \in N^{|P|}=\left\{m\left(p_{1}\right), m\left(p_{2}\right), \ldots, m\left(p_{n}\right)\right\}$ where, $m\left(p_{x}\right)$ is the number of tokens in any place $p_{z}, z=1$ to $n$. $M_{0}$ is the initial marking.
- Definition of enabled transition: The transition is enabled, when the number of tokens in a place $p$ in marking $M$ is greater than or equal to the number of tokens to be removed from place $p$ for a transition $t$. The enabling condition of any transition $t$ can be written as

$$
M(p) \geq I^{-}(p, t), \forall p \in P
$$

- Pre-set and post-set of transition: The preset and postset of transition is denoted by $t$ and $t$. respectively. The preset and postset is set of all places which have outgoing and incoming edges from transition $t$, respectively.

$$
\left\{\begin{array}{l}
\cdot t:=\left\{p \in P \mid I^{-}(p, t)>0\right\} \\
t \cdot:=\left\{p \in P \mid I^{+}(p, t)>0\right\}
\end{array}\right.
$$

- Pre-set and post-set of place: The preset and postset of a place is denoted by $\cdot p$ and $p \cdot$, respectively. The preset and postset is set of all transition which has outgoing and incoming edges from place $p$, respectively. The preset and postset of a place is analogous to preset and postset of transition.

$$
\left\{\begin{array}{l}
\cdot p:=\left\{t \in T \mid I^{-}(p, t)>0\right\} \\
p \cdot:=\left\{t \in T \mid I^{+}(p, t)>0\right\}
\end{array}\right.
$$

- Subsequent marking: When an enabled transition is fired, then tokens are removed from the input places and added to the output places. The number of tokens removed and added to the input and output places is obtained from backward $I^{-}(p, t)$ and forward $I^{+}(p, t)$ incident function, respectively. The change of the previous marking $M$ to a subsequent marking $M^{\prime}$ is defined as:

$$
M^{\prime}(p)=M(p)-I^{-}(p, t)+I^{+}(p, t)
$$

\section{Generlized Stochastic Petri Net Alogorithm For ASSET MANAGMENT}

\section{A. Data Structure}

- Local clock $(L C)$ : The local clock is variable which store firing time of the transition and sets it back to zero when the transition is fired and the given marking is changed.

- Global clock $(G C)$ : The global clock is the variable with an initial value equal to zero. It gets incremented each instance when a transition fires, by an amount equal to the firing time of the transition. The global clock is not incremented when an immediate transition is fired, as the firing time of the immediate transition is zero.

- Enabling condition of transition ( $T K_{\text {index }}$ and $T K_{\text {num }}$ ): Matrix E contains the number of tokens required to enable the transitions. $T K_{\text {index }}$ is a vector which stores the index of all the places of a transition which has tokens in matrix E. The matrix $E \rightarrow P \times T$ has size $n \times m$. The index of place $P$ (row of the matrix) and transition $T$ (column of the matrix) is $z=1$ to $n$ and $y=1$ to $m$, respectively. The element of matrix $E$ can be donated as $E_{z y}$. Thus, 
the index $z$ of all the places of a transition is stored in $T K_{\text {index }}$ if a token exit in the place and number of token in that place is stored in $T K_{\text {num }}$. Both the vectors are employed find the enabled transitions by comparing them with the vector of a marking.

- Enabled transition $\left(T_{\text {enabled }}\right): T_{\text {enabled }}$ is the vector of enabled transitions in a given marking.

- Firing time of enabled transition $\left(T_{\text {fire }}\right): T_{\text {fire }}$ is the vector of firing time of the enabled transitions in a given marking.
- Fired transition $\left(f_{\text {trans }}\right)$ and its firing time $\left(f_{\text {time }}\right)$ : $f_{\text {trans }}$ and $f_{\text {time }}$ is the variable which stores fired transition and its firing time, respectively.

- List of fired transition and firing time of transition (List): List is the vector of tuples which store fired transition and its firing time of all the transitions in a simulation run together in a form list, $\operatorname{List}\left[\left(f_{\text {trans }}, f_{\text {time }}\right)\right]$.

The algorithm is shown in Table I.

B. Algorithm

TABLE I. Generalized Stochastic Petri Net

\begin{tabular}{|c|c|}
\hline \multicolumn{2}{|r|}{$\begin{array}{ll}\text { Algorithm: Generalized Stochastic Petri Net } \\
\end{array}$} \\
\hline \multirow{2}{*}{\multicolumn{2}{|c|}{$\begin{array}{l}\text { Input: } 8 \text { tuple: }\left[P^{c}, T^{c}, T_{1}^{c}, T_{2}^{c}, W_{o}^{c}(U), I^{c^{-}}, I^{c^{+}}, M_{o}^{c}\right] \text { for all subcomponents } c \in C \\
L^{c}, \text { Vector of lifetime of all the subcomponents } \\
E \text {, Enabled transition condition matrix } E \rightarrow P \times T \text { of size } n \times m \\
r, \text { Number of simulation runs or steps } \\
\text { Output: List, List of fired transitions and their firing time in each simulation run }\end{array}$}} \\
\hline & \\
\hline 1 & \multirow{9}{*}{$\begin{array}{l}\text { run } \leftarrow 1 \\
\text { While run } \leq r \text { do: } \\
\text { For each subcomponent } c \in C \text { do: } \\
\qquad \begin{array}{l}\text { Gife } \leftarrow 0 \\
\quad M_{\text {init }} \leftarrow l^{c} / / \text { Life of a subcomponent } c, l^{c} \in L^{c} / / \\
\text { While } G C \leq \text { Life do: } \\
\quad T_{\text {enabled }} \leftarrow \phi, T_{\text {fire }} \leftarrow \phi \text {, and List } \leftarrow \phi\end{array}\end{array}$} \\
\hline 2 & \\
\hline 3 & \\
\hline 4 & \\
\hline 5 & \\
\hline 6 & \\
\hline 7 & \\
\hline 8 & \\
\hline 9 & \\
\hline 10 & \multirow{6}{*}{ For $y=1$ to $m$ do: } \\
\hline 11 & \\
\hline 12 & \\
\hline 13 & \\
\hline 14 & \\
\hline 15 & \\
\hline 16 & End For \\
\hline 17 & $N e w T K_{\text {index }} \leftarrow \phi$ \\
\hline 18 & For all $t k_{\text {index }} \in T K_{\text {index }} \mathbf{d o :}$ \\
\hline 19 & $N e w T K_{\text {index }} \leftarrow\left[M\left[t k_{\text {index }}\right]\right]$ \\
\hline 20 & End For \\
\hline 21 & If $N e w T K_{\text {index }}=T K_{\text {value }}$ Then: \\
\hline 22 & $T_{\text {enabled }} \leftarrow\left[t_{j}\right] / /$ Store enabled transitions in $T_{\text {enabled }}$ vector $/ /$ \\
\hline 23 & End If \\
\hline 24 & End For \\
\hline 25 & \multirow{7}{*}{ 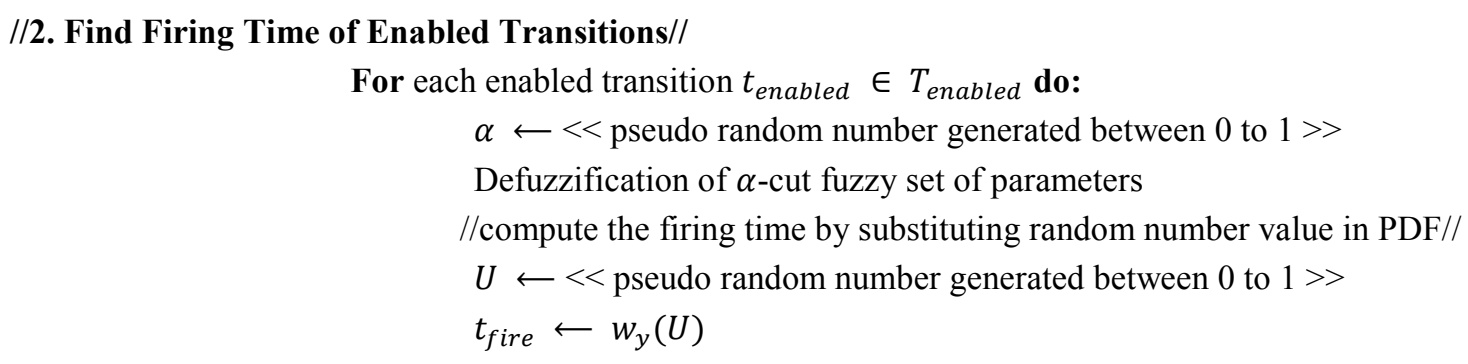 } \\
\hline 26 & \\
\hline 27 & \\
\hline 28 & \\
\hline 29 & \\
\hline 30 & \\
\hline 31 & \\
\hline
\end{tabular}




\begin{tabular}{|c|c|}
\hline 32 & $T_{\text {fire }} \leftarrow\left[t_{\text {fire }}\right] / /$ Store firing time of each transition in $T_{\text {fire }}$ vector// \\
\hline 33 & End For \\
\hline 34 & //3. Find Transition to be Fired and its Firing Time// \\
\hline 35 & $f_{\text {index }}=0$ \\
\hline 36 & $L C=t_{\text {fire }}[0] / /$ First number in $T_{\text {fire }}$ vector is assumed local clock, which should \\
\hline 37 & be minimum firing time of all enabled transitions// \\
\hline 38 & For $f=1$ to length of $T_{\text {fire }}$ array, $t_{\text {fire }} \in T_{\text {fire }}$ do: \\
\hline 39 & If $t_{\text {fire }}[f]<L C$ Then: \\
\hline 40 & $L C=t_{\text {fire }}[f]$ \\
\hline 41 & $f_{\text {index }}=f$ \\
\hline 42 & End If \\
\hline 43 & End For \\
\hline 44 & $f_{\text {time }} \leftarrow L C$ \\
\hline 45 & $f_{\text {trans }} \leftarrow T_{\text {enabled }}\left[f_{\text {index }}\right]$ \\
\hline 46 & //4. Update Marking to Fire Transition// \\
\hline 47 & $M_{\text {init }} \leftarrow M_{o}-I^{c^{-}}+I^{c^{+}}$ \\
\hline 48 & $G C \leftarrow G C+L C \quad / /$ Update global clock by adding local clock time// \\
\hline 49 & $L C \leftarrow 0 \quad / /$ Set local clock time back to zero// \\
\hline 50 & List $\leftarrow\left[\left(f_{\text {trans }}, f_{\text {time }}\right)\right]$ \\
\hline 51 & End While \\
\hline 52 & Return List \\
\hline 53 & End For \\
\hline 54 & run $=$ run +1 \\
\hline 55 & End While \\
\hline
\end{tabular}

\section{EXAMPLE: COMPONENTS OF RAILWAY SWITCHES AND CROSSING}

In this section, an example is presented to demonstrate the implementation of GSPN on components of railway switches and crossings (S\&C). It allows trains to move across the track in a different direction. They are crucial in diverting train on a different route in the event of traffic congestion and line failure. The basic structure of S\&C is shown in Fig. 4.

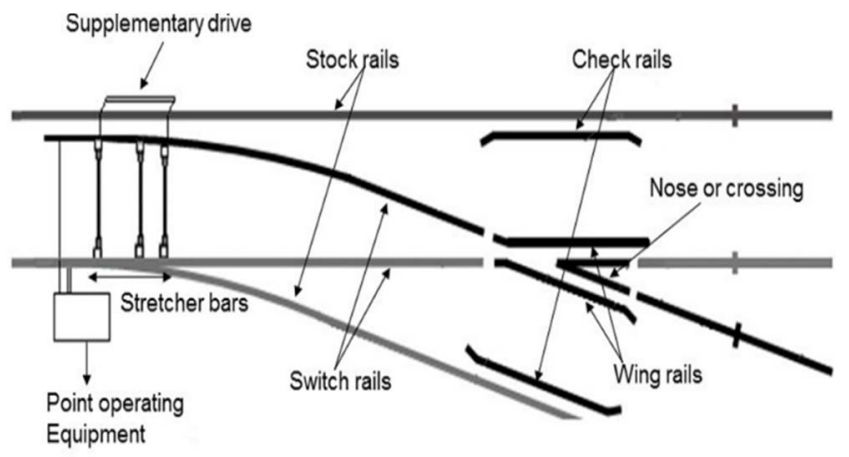

Fig. 4. Basic structure of railway switches \& crossings

Railway tracks are fixed to the ground, however, S\&C at track diversion has moveable components which are most susceptible to failure. In this example, asset management policy is evaluated for two important components of $\mathrm{S} \& \mathrm{C}$, supplementary drive and slide chair. The number of interventions like renewals and repairs for a time horizon of 35 years in the UK railway network is estimated.

\section{A. Supplementary drive}

The supplementary drive ensures the correct positioning of switch rails. It transfers some of the motion of the switch toes to the switch heel of a long switch.

In Fig. 5, place A to $C$ represents a different state of the supplementary drive. Place A is marked when a supplementary drive is renewed. After renewal in time $t_{1}=0$ it starts operating in defect-free state and in $t_{2}$ time units, sampled from $T_{2}$ Weibull distribution the supplementary drive will reach defective state. Visual inspection is carried out to ensure correct setup of a supplementary drive. Place D is marked when a supplementary drive is not under inspection. It is inspected at fixed time-interval $t_{3}$. The transition $t_{7}$ fires to mark no inspection state $\mathrm{D}$, when a supplementary drive is operating in a good state and visual inspection is carried out. Marking in place E represents visual inspection. If a supplementary drive is in defective state $\mathrm{C}$ then the transition $t_{4}$ fires after inspection task at place $\mathrm{E}$ to undertake the minimum action such as speed restriction and traffic control. The minimum action is represented by place F. The follow-up action such as adjustment of wide gauge, obstacle removal and tightening represented by place $G$ is carried out after $t_{5}$ time. After the end of follow up action the 
token moves to state $\mathrm{B}$ and $\mathrm{D}$. The dotted line in $t_{4}, t_{7}$, and $t_{9}$ transition implies that the token is deposited in both input and out places of the transitions.

The renewal process of a supplementary drive is represented by $\mathrm{H}-t_{8}-\mathrm{I}-t_{9}-\mathrm{A} \& \mathrm{H}$. Place $\mathrm{H}$ is marked until it is within its lifetime. The transition $t_{8}$ fires at the end-oflifetime for renewal (I), $t_{9}$ is the time required to renew a supplementary drive. Firing of transition $t_{9}$ resets the system to its initial state $\mathrm{H}=1, \mathrm{~A}=1$ and $\mathrm{D}=1$ (one token in each place).

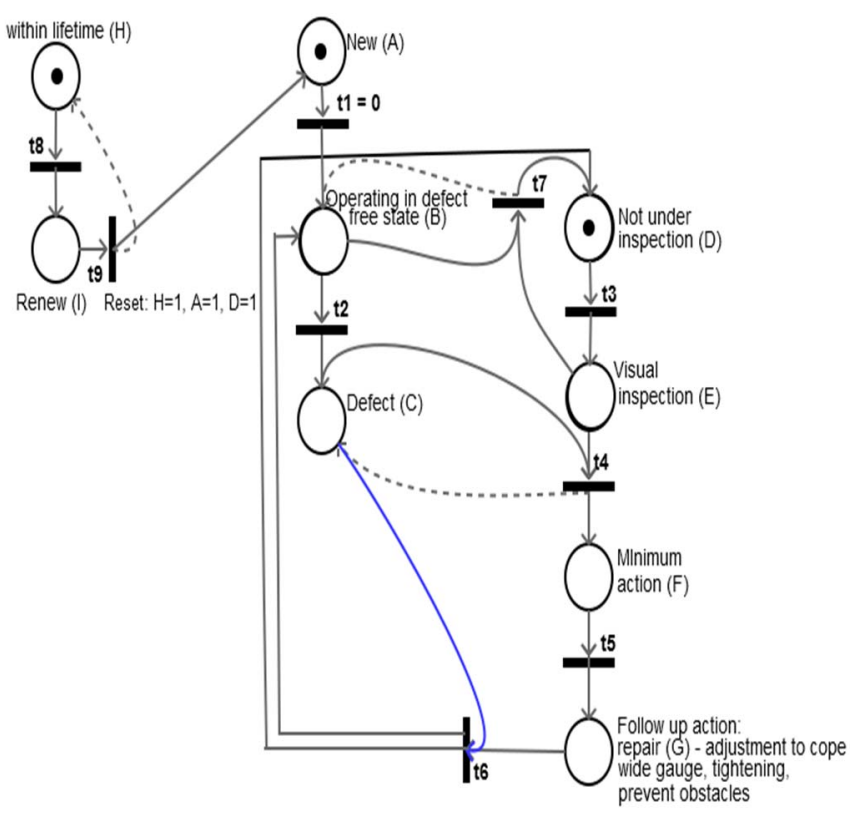

Fig. 5. Supplementary drive

\section{B. Slide chair}

A conventional slide chair supports a switch rail and helps it to slide over its flat surface. It also provides flexible attachment for the stock rail. In Fig. 6, initial state after renewal or new installation is represented by marking at place A and I, which indicates the new state of all slide-chairs and operation within the planned lifetime, respectively. The change of state of the slide-chairs is represented by A-t1-B$t_{2}-\mathrm{C}$ and $\mathrm{A}-t_{1}-\mathrm{B}-t_{3}-\mathrm{B}$. From new state $\mathrm{A}$ the slide-chair immediately transits to state $\mathrm{B}$ for operation in a good state. From state $\mathrm{B}$, the conflicting transitions either $t_{2}$ or $t_{3}$ will fire based on the probability of firing to state $C$ of defective and state $\mathrm{D}$ of broken slide-chair, respectively. The firing time for transition $t_{2}$ and $t_{3}$ is sampled from Weibull distribution $T_{2}$ and $T_{3}$. The transition $T_{2}$ and $T_{3}$ are selected to fire in time $t_{2}$ and $t_{3}$, when they are enabled by having token in place $B$ and are selected by probability $\frac{\lambda_{1}}{\lambda_{1}+\lambda_{2}}$ and $\frac{\lambda_{2}}{\lambda_{1}+\lambda_{2}}$, respectively. The place $E$ and $F$ represent the not under inspection and visual inspection process of slide-chair. It is inspected at fixed time $t_{4}$. The inspection $(\mathrm{F})$ during good state (B) of slide-chair transits it immediately to not under inspection state $(\mathrm{E})$. The repair or replacement indicated by place $\mathrm{G}$ and $\mathrm{H}$ is carried out once the defective state of fastening is recognized. Both repair and replacement (partial renewal) of any defective slide-chair returns all slide-chair to good condition (B) and not under inspection state (E), which is achieved when either transition $t_{8}$ or $t_{9}$ fires.
The complete renewal that is, replacement of all slidechair is carried out immediately after the completion of a planned or designed lifetime. The complete renewal process is represented by $\mathrm{I}-T_{10}-\mathrm{J}-T_{11}-\mathrm{A}$ and $\mathrm{I}$.

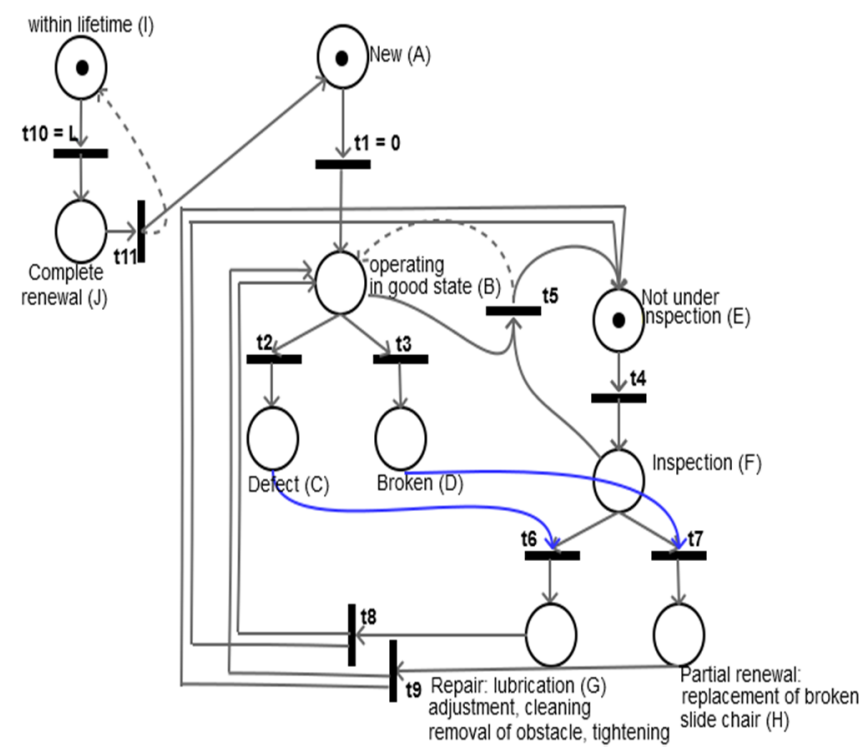

Fig. 6. Slide Chair

A light rail transit (LRT) lines have a light volume of traffic compared to heavy rail transit (HRT) line. The maintenance policy is the same for components in both lines. However, the impact of traffic on S\&C components in both the line would be different. The parameters to evaluate the effect of set maintenance policy on supplementary drives and slide chairs in both LRT and HRT lines are different, as shown in Table II and III. The cumulative average number of interventions for both LRT and HRT line in supplementary drive and slide chair is shown in Fig. 7 to 10. Overall in both components, the total number of interventions are high in HRT compared to LRT. A supplementary drive would have 1 complete and partial renewal in 20 years whereas the LRT line would have a partial and complete renewal in 30 years. It increases further after 30 years. A supplementary drive at HRT line would undergo more control action than LRT line. Similarly, a slide chair would need complete renewal in 15 years at HRT line than 20 years at LRT line. The occurrence of repair in both lines appears same, however, partial renewal at HRT line would be much higher than LRT line.

TABLE II. PARAMETERS FOR SUPPLEMENTARY DRIVE

\begin{tabular}{|c|c|c|c|c|}
\hline $\begin{array}{c}\text { Transitio } \\
n \text { (days) }\end{array}$ & $\begin{array}{c}\text { Type of } \\
\text { Transition }\end{array}$ & $\begin{array}{c}\text { Sample } \\
\text { Distrib } \\
\text { ution }\end{array}$ & $L R T$ & $H R T$ \\
\hline$t_{1}$ & Immediate & - & 0 & 0 \\
\hline \multirow[b]{2}{*}{$t_{2}$} & \multirow[b]{2}{*}{ Stochastic } & \multirow[b]{2}{*}{$\begin{array}{c}\text { Weibul } \\
1\end{array}$} & $\beta=1.5$ & $\beta=2.5$ \\
\hline & & & $\begin{array}{c}\text { Triangular } \\
\text { fuzzy } \\
\text { number } \\
\eta=(4900, \\
5475,7000)\end{array}$ & $\begin{array}{c}\text { Triangular } \\
\text { fuzzy } \\
\text { number } \\
\eta=(3000 \\
3650,4500)\end{array}$ \\
\hline$t_{3}$ & Deterministic & - & 180 & 90 \\
\hline$t_{4}$ & Deterministic & - & 1 & 1 \\
\hline
\end{tabular}




\begin{tabular}{|c|c|c|c|c|}
\hline $\begin{array}{c}\text { Transitio } \\
n \text { (days) }\end{array}$ & $\begin{array}{c}\text { Type of } \\
\text { Transition }\end{array}$ & $\begin{array}{c}\text { Sample } \\
\text { Distrib } \\
\text { ution }\end{array}$ & $L R T$ & $H R T$ \\
\hline \multirow{2}{*}{$t_{5}$} & \multirow{2}{*}{ Stochastic } & \multirow{2}{*}{$\begin{array}{c}\text { Lognor } \\
\text { mal }\end{array}$} & $\mu=15$ & $\mu=10$ \\
\hline & & & $\sigma=2$ & $\sigma=2$ \\
\hline$t_{6}$ & Deterministic & - & 1 & 1 \\
\hline$t_{7}$ & Immediate & - & 0 & 0 \\
\hline$t_{8}$ & Deterministic & - & 9125 & 7300 \\
\hline \multirow[t]{2}{*}{$t_{9}$} & \multirow[t]{2}{*}{ Stochastic } & \multirow[t]{2}{*}{$\begin{array}{c}\text { Lognor } \\
\text { mal }\end{array}$} & $\begin{array}{c}\text { Triangular } \\
\text { fuzzy } \\
\text { number } \\
\mu=(50 \\
60,100)\end{array}$ & $\begin{array}{c}\text { Triangular } \\
\text { fuzzy } \\
\text { number } \\
\mu=(25 \\
30,60)\end{array}$ \\
\hline & & & $\sigma=15$ & $\sigma=10$ \\
\hline
\end{tabular}

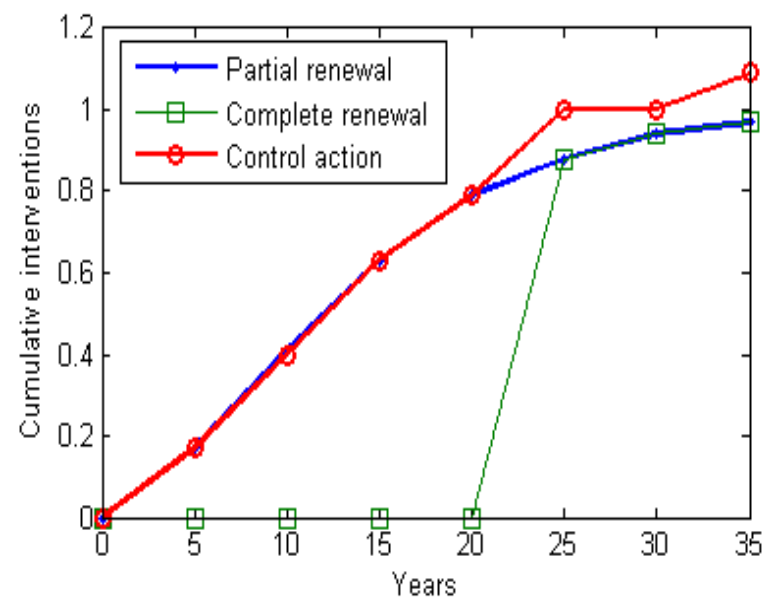

Fig. 7. Cumulative number of interventions in supplementary drive of $\mathrm{S} \& \mathrm{C}$ in LRT line

TABLE III. PARAMETERS FOR SLIDE CHAIR

\begin{tabular}{|c|c|c|c|c|}
\hline $\begin{array}{c}\text { Transit } \\
\text { ion } \\
\text { (days) }\end{array}$ & $\begin{array}{c}\text { Type of } \\
\text { Transition }\end{array}$ & $\begin{array}{c}\text { Sample } \\
\text { Distributi } \\
\text { on }\end{array}$ & $L R T$ & $H R T$ \\
\hline$t_{1}$ & Immediate & - & 0 & 0 \\
\hline \multirow[b]{2}{*}{$t_{2}$} & \multirow[b]{2}{*}{ Stochastic } & \multirow[b]{2}{*}{ Weibull } & $\beta=1.6$ & $\beta=2$ \\
\hline & & & $\begin{array}{c}\begin{array}{c}\text { Triangular } \\
\text { fuzzy } \\
\text { number }\end{array} \\
\eta=(3000, \\
3650,4500)\end{array}$ & $\begin{array}{c}\begin{array}{c}\text { Triangular } \\
\text { fuzzy } \\
\text { number }\end{array} \\
\eta=(2500 \\
2800,3500)\end{array}$ \\
\hline \multirow[b]{2}{*}{$t_{3}$} & \multirow[b]{2}{*}{ Stochastic } & \multirow[b]{2}{*}{ Weibull } & $\beta=2$ & $\beta=2.5$ \\
\hline & & & $\begin{array}{c}\begin{array}{c}\text { Triangular } \\
\text { fuzzy } \\
\text { number }\end{array} \\
\eta=(3000 \\
3650,4500)\end{array}$ & $\begin{array}{c}\begin{array}{c}\text { Triangular } \\
\text { fuzzy } \\
\text { number }\end{array} \\
\eta=(2500 \\
2800,3500)\end{array}$ \\
\hline$t_{4}$ & Deterministic & - & 180 & 90 \\
\hline$t_{5}$ & Immediate & - & 0 & 0 \\
\hline$t_{6}$ & Deterministic & - & 1 & 1 \\
\hline$t_{7}$ & Deterministic & - & 1 & 1 \\
\hline \multirow{2}{*}{$t_{8}$} & \multirow{2}{*}{ Stochastic } & \multirow{2}{*}{$\begin{array}{c}\text { Lognorm } \\
\text { al }\end{array}$} & $\mu=2$ & $\mu=1$ \\
\hline & & & $\sigma=2$ & $\sigma=1$ \\
\hline \multirow{2}{*}{$t_{9}$} & \multirow{2}{*}{ Stochastic } & \multirow{2}{*}{$\begin{array}{c}\text { Lognorm } \\
\text { al }\end{array}$} & $\mu=60$ & $\mu=30$ \\
\hline & & & $\sigma=15$ & $\sigma=10$ \\
\hline$t_{10}$ & Deterministic & - & 9125 & 7300 \\
\hline \multirow[t]{2}{*}{$t_{11}$} & \multirow[t]{2}{*}{ Stochastic } & \multirow[t]{2}{*}{$\begin{array}{c}\text { Lognorm } \\
\text { al }\end{array}$} & $\begin{array}{c}\text { Triangular } \\
\text { fuzzy } \\
\text { number } \\
\mu=(50, \\
62,100)\end{array}$ & $\begin{array}{c}\text { Triangular } \\
\text { fuzzy } \\
\text { number } \\
\mu=(25 \\
33,60)\end{array}$ \\
\hline & & & $\sigma=15$ & $\sigma=10$ \\
\hline
\end{tabular}

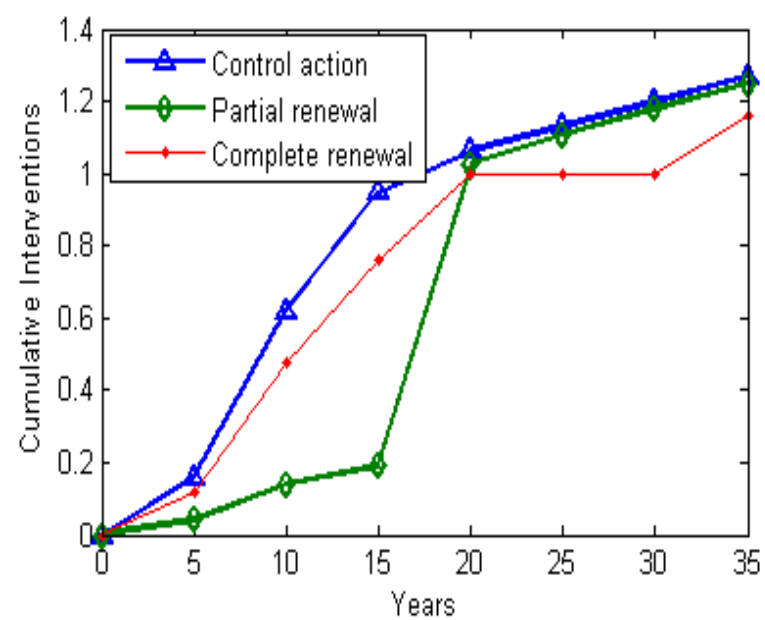

Fig. 8. Cumulative number of interventions in supplementary drive of $\mathrm{S} \& \mathrm{C}$ in HRT line

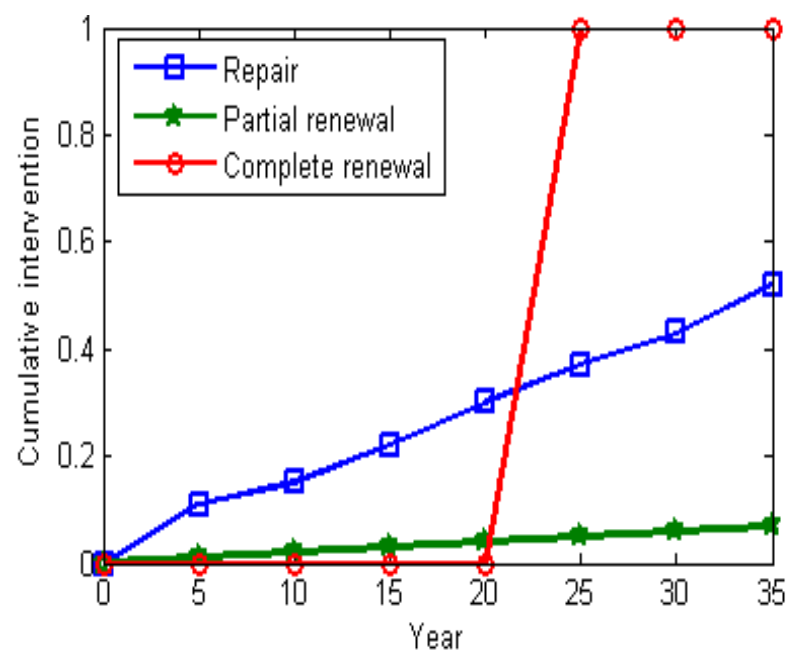

Fig. 9. Cumulative number of interventions in slide chair of $S \& C$ in LRT line 


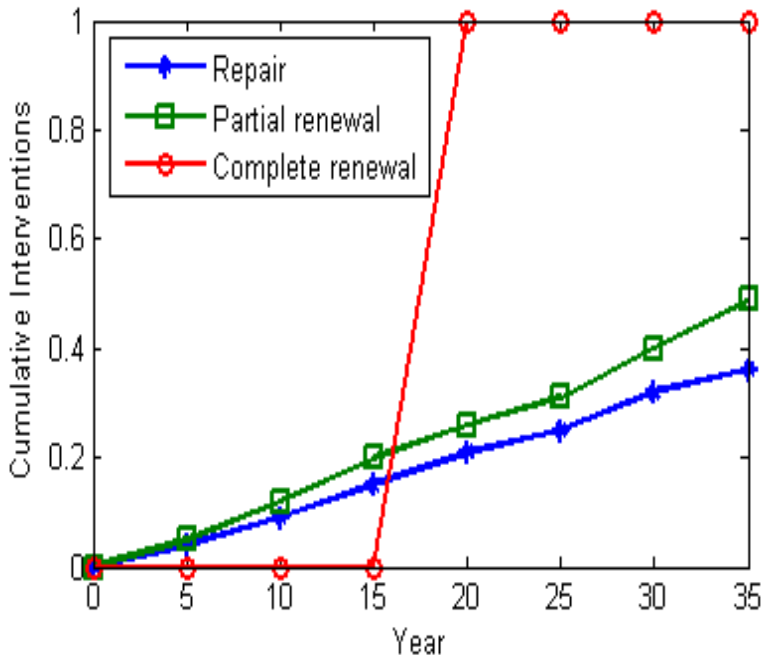

Fig. 10. Cumulative number of interventions in slide chair of S\&C in HRT line

\section{CONCLUSION}

This paper presents an algorithm based on Generalized Stochastic Petri Net (GSPN) with fuzzy parameters to evaluate the policies designed to enhance the reliability and availability of infrastructural assets. The infrastructure asset management policy evaluation support decision-makers in assessing the maintenance policy of a target asset. The GSPN is a graphical and mathematical representation tool for the random, concurrent and synchronized processes in a system. The infrastructural assets management policy is the set of rules for maintenance actions such as repair, control actions and partial \& complete renewal on a given state of an asset. The proposed algorithm and example on railway switches and crossing have shown a method to integrate maintenance, inspection, and degradation process of an asset. The parameters in GSPN can be stochastic and fuzzy which can incorporate randomness and uncertainty in the system, respectively. It can estimate the effect and needs of maintenance actions for a different state of the asset over the planning period.

\section{ACKNOWLEDGMENT}

We are thankful for funding for this research work by the Alliance Strategic Grant at Manchester Business School, The University of Manchester, UK and In2Rail, a Horizon 2020 project.

\section{REFERENCES}

[1] G. A. Agha, F. De Cindio and G. Rozenberg. Concurrent ObjectOriented Programming and Petri Nets: Advances in Petri Nets. Springer, 2001.

[2] C. Lindemann, "Performance modelling with deterministic and stochastic Petri nets". ACM sigmetrics performance evaluation review, Vol.26, no.2, pp.3, 1998

[3] W. M. Van Der Aalst, "Making work flow: On the application of petri nets to business process management." In International conference on application and theory of Petri nets, pp. 1-22. Springer, Berlin, Heidelberg, 2002.

[4] A. Rogge-Solti and M. Weske, "Prediction of business process durations using non-Markovian stochastic Petri nets," Information Systems, Vol. 54, pp. 1-14, 2015.
[5] W. M. Van der Aalst, "Business process management as the "Killer App" for Petri nets," Software \& Systems Modeling, Vol 14, no.2, pp.685-691, 2015.

[6] J. Clempner, "Verifying soundness of business processes: A decision process Petri nets approach," Expert Systems with Applications, Vol. 41, no.11, pp. 5030-5040, 2014

[7] Y. W. Si, V.I. Chan, M. Dumas, and D. Zhang, "A Petri Nets based Generic Genetic Algorithm framework for resource optimization in business processe," Simulation Modelling Practice and Theory, Vol. 86, pp.72-101, 2018.

[8] Z. Ding, H. Qiu, R. Yang, C. Jiang, M. Zhou, "Interactive-controlmodel for Human-computer Interactive System Based on Petri Nets," IEEE Transactions on Automation Science and Engineering, Vol. 16, no.4, pp. 1800-1813, 2019.

[9] Y. Chen, Z. Li, K. Barkaoui, N. Wu, M. Zhou, and,"Compact supervisory control of discrete event systems by Petri nets with data inhibitor arcs," IEEE Transactions on Systems, Man, and Cybernetics: Systems Vol. 47, no. 2, pp. 364-379, 2016.

[10] Y. S. Huang, Y. S. Weng, and M. Zhou, "Design of traffic safety control systems for emergency vehicle preemption using timed Petri nets," IEEE Transactions on Intelligent Transportation Systems, Vol. 16, no. 4, pp. 2113-2120, 2015.

[11] J. Ezpeleta, J . M. Colom, and J. Martinez, "A Petri net based deadlock prevention policy for flexible manufacturing systems," IEEE transactions on robotics and automation, Vol. 11, no. 2, pp. 173-184, 1995.

[12] H. Hu, Y. Liu, and M. Zhou, "Maximally permissive distributed control of large scale automated manufacturing systems modeled with Petri nets," IEEE Transactions on Control Systems Technology, Vol. 23, no. 5, pp. 2026-2034, 2015.

[13] J. M. Leigh and S. J. Dunnett, "Use of Petri nets to model the maintenance of wind turbines," Quality and Reliability Engineering International, Vol. 32, no.1, pp. 167-180, 2016.

[14] F. P. Santos, A.P. Teixeira, and C. G. Soares, "Maintenance planning of an offshore wind turbine using stochastic Petri nets with predicates," Journal of Offshore Mechanics and Arctic Engineering, Vol. 140, no. 2, pp. 021904, 2018

[15] J. Andrews, D. Prescott, and F. De Rozières, "A stochastic model for railway track asset management," Reliability Engineering \& System Safety, Vol. 130, pp. 76-84, 2014.

[16] D. Zhang, H. Hu, and C. Roberts, "Rail maintenance analysis using Petri nets," Structure and Infrastructure Engineering, Vol. 13, no.6, pp. 783-793, 2017.

[17] D. Prescott and J. Andrews, "A track ballast maintenance and inspection model for a rail network," Proceedings of the Institution of Mechanical Engineers, Part O: Journal of risk and reliability, vol. 227, no. 3, pp. 251-266, 2013.

[18] J. Andrews, "A modelling approach to railway track asset management," Proceedings of the Institution of Mechanical Engineers, Part F: Journal of Rail and Rapid Transit, Vol. 227, no. 1, pp. 56-73, 2013.

[19] P. C. Yianni, D. Rama, L.C. Neves, J. D. Andrews, and D. Castlo, “A Petri-Net-based modelling approach to railway bridge asset management," Structure and Infrastructure Engineering, Vol. 13, no. 2, pp.287-297, 2017.

[20] B. Le and J. Andrews, "Petri net modelling of bridge asset management using maintenance-related state conditions," Structure and Infrastructure Engineering, Vol. 12, no. 6, pp. 730-751, 2016.

[21] F. A. Rahmani, L. Hosseinzadeh Lotfi, R. M. Rostamy-Malkhalifeh, and A. Tofigh, "A new method for defuzzification and ranking of fuzzy numbers based on the statistical beta distribution," Advances in Fuzzy Systems, Vol. 2016, 2016

[22] Y. M. Wang, "Centroid defuzzification and the maximizing set and minimizing set ranking based on alpha level sets," Computers \& Industrial Engineering, Vol. 57, no. 1, pp. 228-236, 2009. 